\title{
OPEN Leukotoxin (LtxA/Leukothera) induces ATP expulsion via pannexin-1 channels and subsequent cell death in malignant lymphocytes
}

Derek J. Prince ${ }^{1}$, Deendayal Patel ${ }^{2} \&$ Scott C. Kachlany ${ }^{1 凶}$

Leukotoxin (LtxA) (Trade name, Leukothera) is a protein that is secreted from the oral bacterium Aggregatibacter actinomycetemcomitans, which targets and kills activated white blood cells (WBCs) by binding to lymphocyte function associated antigen-1 (LFA-1). Interaction between LtXA and Jurkat T-cells results in cell death and is characterized by increased intracellular $\mathrm{Ca}^{2+}$, activation of caspases, clustering of LtXA and LFA-1 within lipid rafts, and involvement of the Fas death receptor. Here, we show that LtxA can kill malignant lymphocytes via apoptotic and necrotic forms of cell death. We show that LtXA causes activation of caspases and PARP, cleavage of pannexin-1 (Panx1) channels, and expulsion of ATP, ultimately leading to cell death via apoptosis and necrosis. CRISPR-Cas9 mediated knockout $(\mathrm{K} / \mathrm{O})$ of Panx1 in Jurkat cells prevented ATP expulsion and resulted in resistance to LtXA for both apoptotic and necrotic forms of death. Resistance to necrosis could only be overcome when supplementing LtxA with endogenous ATP (bzATP). The combination of LtxA and bzATP promoted only necrosis, as no Panx1 K/O cells stained positive for phosphatidylserine (PS) exposure following the combined treatment. Inhibition of LtXA/bzATP-induced necrosis was possible when pretreating Jurkat cells with oATP, a P2 $X_{7} R$ antagonist. Similarly, blockage of $P 2 X_{7} R s$ with oATP prevented the intracellular mobilization of $\mathrm{Ca}^{2+}$, an important early step in LtxA induced cell death. We show that LtxA is able to kill malignant lymphocytes through an apoptotic death pathway which is potentially linked to a Panx1/P2X 7 mediated necrotic form of death. Thus, inhibition of ATP release appears to significantly delay the onset of LtxA induced apoptosis while completely disabling the necrotic death pathway in T-lymphocytes, demonstrating the crucial role of ATP release in LtXA-mediated cell death.

Aggregatibacter actinomycetemcomitans (A. actinomycetemcomitans) is a Gram-negative oral bacterium found in the oral flora of healthy individuals and patients with aggressive periodontitis. The bacterium produces several virulence factors such as leukotoxin (LtxA), cytolethal distending toxin, immunosuppression factors, lipopolysaccharides, surface antigens, and heat shock proteins, among others, to promote disease in the oral cavity such as aggressive periodontal diseases ${ }^{1}$. Perhaps the most important virulence factor produced by A. actinomycetemcomitans is that of LtxA, a 113 kilodalton $(\mathrm{kDa})$ protein strategically secreted to suppress the host immune response to promote the pathogenicity of A. actinomycetemcomitans ${ }^{2,3}$. Immune suppression is achieved as LtxA specifically targets and kills activated white blood cells (WBCs) by binding to lymphocyte function-associated antigen-1 (LFA-1). LFA-1 is a $\beta 2$ integrin [a (CD11a) and $\beta$ (CD18)] expressed on hematopoietic cells ${ }^{3}$. The primary role of the integrin is to promote leukocyte adhesion through interaction with intercellular adhesion molecules (ICAMs), which can lead to cellular migration and activation ${ }^{4,5}$. In a cellular resting state, LFA-1 is configured in a bent or inactive affinity. Only when activation stimuli (e.g. chemokines and cytokines) are sensed do LFA-1 presenting cells express LFA-1 in its extended or "activated" state ${ }^{6}$. It is this state that initiates the pro-inflammatory/migratory response. Therefore, activation of LFA-1 plays a role in the migration of immune cells to the appropriate tissue in order to establish an inflammatory response and promote diapedesis, as the ability of immune cells to penetrate into tissues depends on activated LFA- $1^{6,7}$. For this reason, LFA-1 is 


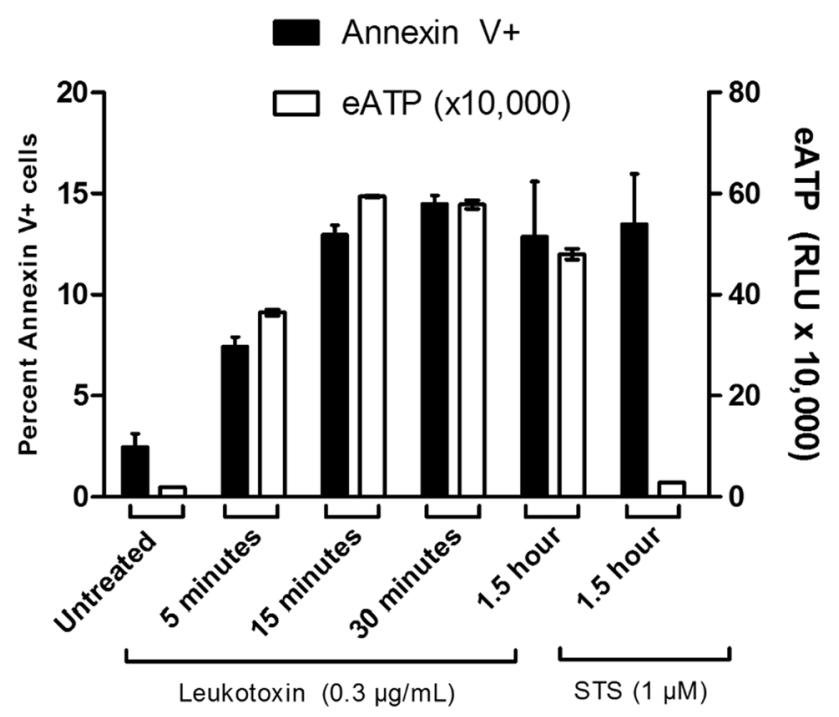

Figure 1. ATP is expelled from Jurkat cells following LtxA treatment. Wild-type Jurkat cells were left untreated or treated with $0.3 \mu \mathrm{g} / \mathrm{mL}$ of LtxA for varying time points or with $1 \mu \mathrm{M}$ of STS for $1.5 \mathrm{~h}$. Apoptosis was assessed via flow cytometry using the Guava Nexin kit by EMD Millipore through detection of Annexin V. Extracellular ATP (eATP) was measured by immediately spinning down the cells following treatment and measuring the total amount of ATP within cellular supernatants. Apoptosis is expressed as the percentage of gated cells staining positive for Annexin V and eATP is expressed as the percentage of ATP mediated luminescence within sample supernatants compared to the untreated cell control supernatant.

an intriguing therapeutic option for targeting certain white blood cell diseases and inflammatory disorders. In fact, targeting LFA-1 presenting cells with LtxA has already demonstrated significant therapeutic potential in a variety of autoimmune/inflammatory conditions ${ }^{8-10}$. Moreover, it has been observed that LFA-1 is upregulated in many leukemias and lymphomas ${ }^{11-13}$. LtxA has also proven to be an effective single or combination use agent to induce rapid apoptosis in a wide variety of leukemia and lymphoma cell types ${ }^{4,14,15}$. In addition, LtxA has shown targeted activity and safety in mouse models for leukemia and lymphoma ${ }^{4,9,16}$. Therefore, the specific targeting and killing of LFA-1 expressing cells remains an intriguing option for the treatment of hematologic malignancies.

In monocytes, LtxA initiates a lysosomal mediated death pathway where LtxA delivers LFA-1 to lysosomes, disrupting lysosomal integrity and inducing cell death ${ }^{17}$. This was determined via the cytosolic detection of lysosomal-associated membrane protein 1 (LAMP-1) and cathepsin D following LtxA treatment, an indication of lysosomal lysis. However, when this pathway was studied in a lymphocytic leukemia cell model, this lysosomal mediated death mechanism was not observed ${ }^{4}$. Furthermore, Fagerberg et al. shows that an additional mechanism involving ATP release may also be involved in cell death ${ }^{18}$. Instead, it has been established that malignant lymphocytes undergo a LtxA-mediated cell death mechanism that requires the death receptor Fas $(\mathrm{CD} 95)^{19}$. Using Jurkat cells, our lab has shown that LtxA-mediated cell death requires the death receptor Fas and caspase- 8 but not Fas Ligand (Fas-L), implying a non-canonical caspase 8/Fas mediated death pathway ${ }^{4,19}$. However, the precise mechanisms leading up to this pathway and the downstream cascades remain elusive and require further investigation.

In the present work, we sought to better understand the mechanisms of LtxA-mediated cell death of malignant lymphocytes. We report that immediately following LtxA exposure, Jurkat lymphocytes expel ATP via Panx1 channels and the expelled ATP goes on to activate purinergic receptor $\mathrm{P}_{2} \mathrm{X}_{7}\left(\mathrm{P} 2 \mathrm{X}_{7} \mathrm{R}\right)$. As a result, the expelled ATP and activation of $\mathrm{P} 2 \mathrm{X}_{7} \mathrm{R}$ allows the cell to proceed with the mobilization of intracellular $\mathrm{Ca}^{2+}$, caspase activation, and PARP cleavage, all of which are key events required for the LtxA-mediated cell death of Jurkat cells.

\section{Results}

LtxA causes ATP release and cell death (apoptosis) in Jurkat cells. In response to certain cytotoxic and chemotherapeutic agents, transformed lymphocytes have been observed to rapidly (within seconds to minutes) expel ATP in a controlled manner ${ }^{20-23}$. To determine if LtxA causes rapid release of ATP in Jurkat cells, we treated cells with the protein and then measured extracellular ATP. We found that treatment with LtxA $(0.3 \mu \mathrm{g} /$ $\mathrm{mL}$ ) induces the rapid release of ATP from dying malignant lymphocytes in a time-dependent manner (Fig. 1). STS, a well-studied apoptosis inducing compound in Jurkat cells, did not cause an increase in extracellular ATP.

LtxA mediated ATP release is not a result of membrane lysis. The controlled secretion of ATP from dying cells is a known mechanism in certain forms of cell death ${ }^{22}$. To determine if ATP was being released from LtxA treated Jurkat cells in a controlled manner, membrane integrity assays were performed. Following treatment with LtxA, membrane lysis was not observed at the same time points where the maximum early release 


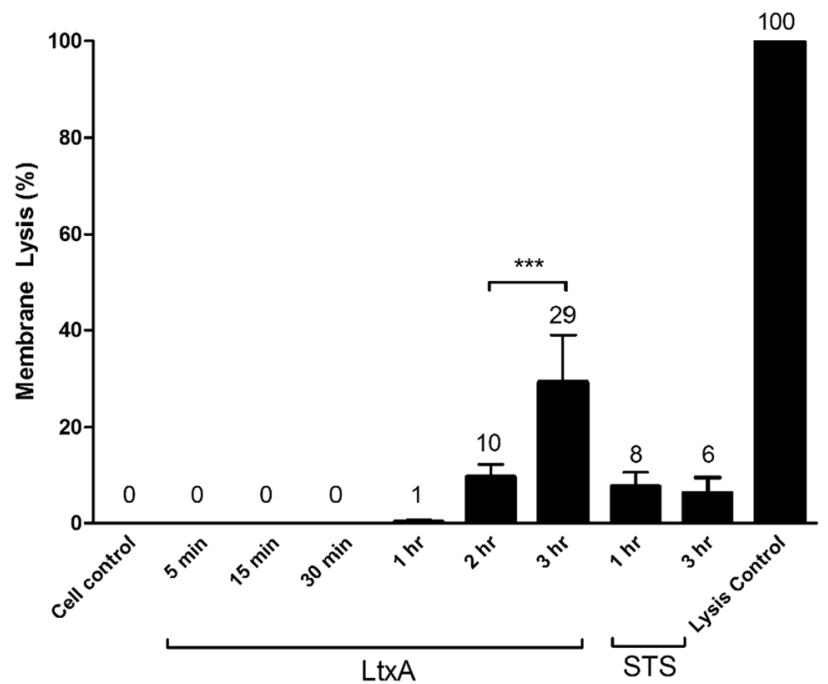

Figure 2. LtxA induced membrane lysis is not the cause of ATP expulsion. Wild-type Jurkat cells were treated with $0.3 \mu \mathrm{g} / \mathrm{mL}$ of LtxA for varying time points or with $1 \mu \mathrm{M}$ of STS for 1 and $3 \mathrm{~h}$. Membrane lysis was assessed using the Cytotox-ONE Homogenous Membrane Integrity Assay from Promega. Membrane lysis is expressed as a percentage of lactate dehydrogenase (LDH) relative to the control cells.

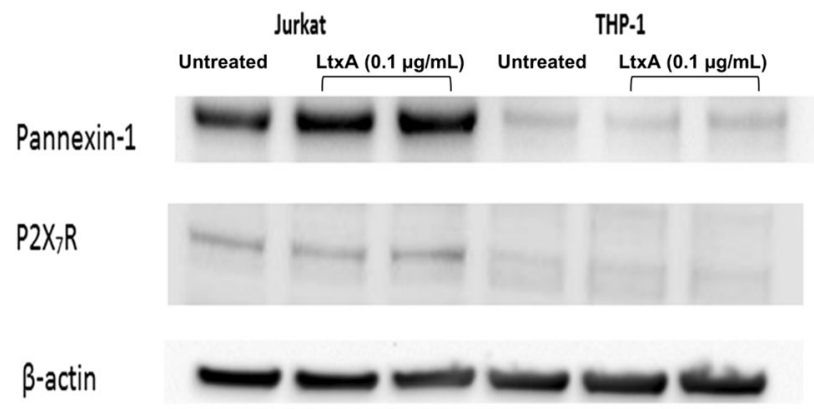

Figure 3. Panx 1 and $P 2 X_{7} R$ expression in Jurkat and THP-1 cells. Wild-type Jurkat and THP-1 cells were left untreated or treated with $0.1 \mu \mathrm{g} / \mathrm{mL}$ of LtxA for $1 \mathrm{~h}$. Western blots were performed to determine the expression of Panx 1 and $\mathrm{P} 2 \mathrm{X}_{7} \mathrm{R}$ protein content. LtxA treatments are shown in duplicate in lanes 2 and 3 and 5 and 6. $\beta$-Actin was used as the loading control. Uncropped gels are presented in Supplementary Figures S1-S3.

of ATP occurred (15-30 min). We observed that notable membrane lysis does not occur until 2-3 h post LtxA treatment (Fig. 2). Thus, the release of ATP precedes the onset of membrane disruption.

Panx1 and $P 2 X_{7} R$ protein expression is present in wild-type Jurkat cells. Since their discovery in the early 2000s, the pannexin families of membrane pore forming proteins have been increasingly linked to the controlled release of ATP from a broad range of cell types ${ }^{24}$. To test the hypothesis that pannexin proteins could play a role in LtxA-mediated ATP release in Jurkat cells, we performed western blot analysis. We found that Jurkat cells express relatively high concentrations of Panx1 protein expression when compared to a malignant monocytic cell line (Fig. 3). Jurkat cells also express $\mathrm{P}_{2} \mathrm{X}_{7}$, but at much lower levels than Panx1. Treatment of Jurkat cells with low concentrations of LtxA $(0.1 \mu \mathrm{g} / \mathrm{mL})$ did not increase the expression of Panx1 or P2X $\mathrm{X}_{7} \mathrm{R}$ wen compared to the cell control. This data indicates that Panxl is expressed and could play an important signaling role in LtxA mediated cell death of Jurkat cells.

Generation of a Jurkat Panx1 knockout cell line using CRISPR/Cas9. Previous studies have reported the importance of Panxl not only as a membrane channel but as a mediator of inflammation and cell death via its release of $\mathrm{ATP}^{25}$. To fully understand the implication of Panx1 as it relates to LtxA mediated cell death of Jurkat cells, a Panx1 knockout was generated using CRISPR/Cas9 methodology. Western blot analysis was performed to determine which sgRNA construct produced the most effective knockout of Panx1 as it relates to total protein expression. Three total sgRNAs were analyzed via transduction. Of the three, sgRNA909 (against Exon 4) completely knocked out Panx1 expression in Jurkat cells (Fig. 4; Lanes 7 and 8) as no Panx1 protein bands were observed at $45 \mathrm{kDa}$ (full product) or $14 \mathrm{kDa}$ (cleaved product). Thus, using this lentiviral based 


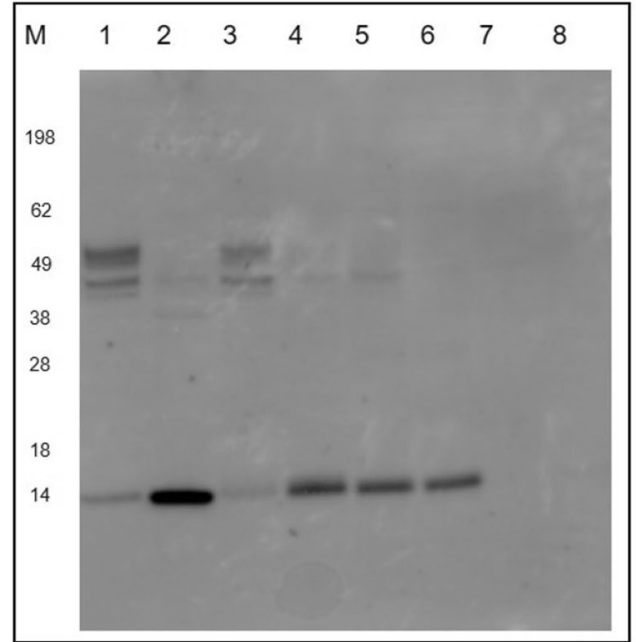

\begin{tabular}{|l|}
\multicolumn{1}{|c|}{ Legend } \\
1. Jurkat wild-type untreated \\
2. Jurkat wild-type + STS \\
3. Jurkat sgRNA907-E1 construct control \\
4. Jurkat sgRNA907-E1 construct + STS \\
5. sgRNA908-E1 construct control \\
6. sgRNA908-E1 + STS \\
7. sgRNA909-E4 construct control \\
8. sgRNA909-E4 + STS \\
M= marker \\
\hline
\end{tabular}

Figure 4. Western blot analysis of Panx1 protein K/O in Jurkat cells. Jurkat cells stably expressing Cas9 were transduced with three different sgRNA's each targeting a different exon sequence of the Panx1 gene: sgRNA907 (exon 1), sgRNA908 (exon 2), and sgRNA909 (exon 4). Analysis was performed with cells that were successfully transduced and that were expanded through the usage of selection media and single cell isolation/cloning. Western blot analysis was performed to determine which sgRNA construct resulted in the most effective knock down of Panx1 total protein expression. Where indicated, cells were treated with staurosporin (STS) at a concentration of $1 \mu \mathrm{M}$ for $3 \mathrm{~h}$. STS, known to mediate the cleavage of Panx1, was included to ensure that the assay can detect and that the cells are responsive to a known cell death inducing agent by detecting cleaved forms of Panx1.The lower band represents cleaved Panx1. $\beta$-Actin was used as the loading control. The uncropped $\beta$-actin gel is presented in Supplementary Figure S4.

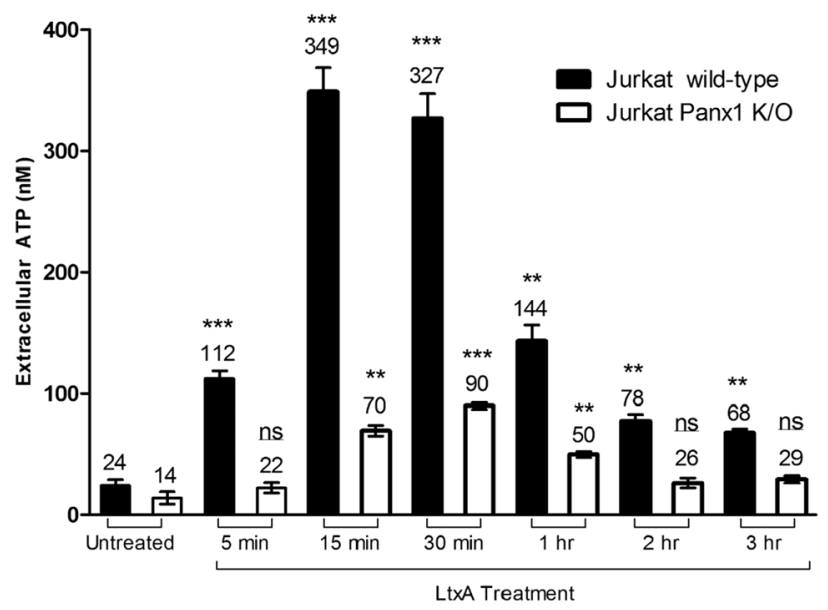

Figure 5. LtxA induced expulsion of ATP from Jurkat wild-type and Panx1 K/O cells. Expulsion of ATP was determined by collecting cellular supernatants of wild-type and Panx1 K/O Jurkat cells following treatments with LtxA or STS and measuring ATP content. Cells were treated with LtxA at a concentration of $0.3 \mu \mathrm{g} / \mathrm{mL}$. ATP quantification was performed using a 5-point standard curve.

transduction approach; we were able to generate a Jurkat cell line with no detectable expression of any isoforms of the Panx1 protein (Fig. 4). Where indicated, cells were treated with staurosporin (STS) at a concentration of $1 \mu \mathrm{M}$ for $3 \mathrm{~h}$. $\beta$-actin was used as the loading control.

Panx1 knockout cells exhibit significantly reduced levels of LtxA induced eATP and apoptosis. We hypothesized that Panx1 channels could be responsible for the early and controlled release of ATP from LtxA treated Jurkat cells. To determine this, extracellular ATP levels of LtxA treated wild-type and Panx1 K/O Jurkat cells were measured. Knockout of the Panx1 channel resulted in significantly less LtxA-induced expulsion of ATP compared to wild-type Jurkat cells (Fig. 5).

To determine if Panxl channels were linked to LtxA mediated cell death, several cell death assays were performed using Jurkat wild-type and Panx1 K/O cells. When LtxA was added to Panx1 K/O cells, apoptosis and 


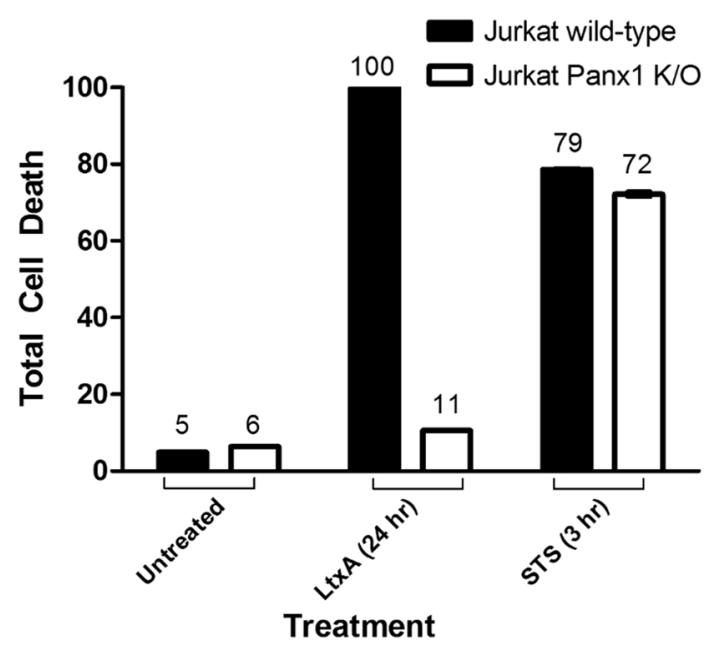

Figure 6. Panx1 K/O cells have reduced sensitivity to LtxA at concentrations of $0.3 \mu \mathrm{g} / \mathrm{mL}$ for as long as $24 \mathrm{~h}$. Jurkat wild-type and Panx1 K/O cells were treated with LtxA for $24 \mathrm{~h}$. Following treatment, Jurkat wild-type cells stained over 100\% positive for Annexin while Panx1 K/O cells showed Annexin staining similar to that of untreated control cells. To assess whether the appropriate apoptotic machinery was functioning properly in Panx1 K/O cells, STS was used as a positive control. Both Jurkat wild-type and Panx1 K/O cells showed similar Annexin staining patterns following treatment with STS. Where indicated, cells were treated with LtxA at a concentration of $0.3 \mu \mathrm{g} / \mathrm{mL}$ for $24 \mathrm{~h}$ or with staurosporin (STS) at a concentration of $1 \mu \mathrm{M}$ for $3 \mathrm{~h}$.

caspase activation were similar to that of the untreated cellular control (Figs. 6, 7). Additionally, LtxA treatment of Panx1 K/O cells resulted in the inhibition of PARP cleavage (an indication of apoptosis) (Lane 5), similar to that of untreated cellular controls (Fig. 8).

LtxA induces two distinct death pathways in Jurkat cells. Recent studies have implicated a link between ATP and P2X $\mathrm{X}_{7}$ Rs in apoptotic and necrotic forms of cell death ${ }^{26}$. For this reason, in addition to our assessment of apoptosis, we decided to also measure LtxA mediated cellular depletion (necrosis). To assess the precise role of $\mathrm{P}_{2} \mathrm{X}_{7} \mathrm{R}$ as a potential mediator of necrotic cell death, oxidized ATP (oATP) was used. oATP is an irreversible inhibitor of macrophage purinergic receptors that works by covalently modifying the receptors nucleotide binding proteins ${ }^{27}$. Blockage of $\mathrm{P}_{2} \mathrm{X}_{7} \mathrm{R}$ with oATP completely inhibited the ability of LtxA to initiate the cellular depletion pathway from proceeding (Fig. 9). In addition, while the typical apoptotic mode of cell death was not completely suppressed, it was significantly decreased (Fig. 9). It was determined that LtxA induces two distinct death pathways: (1) apoptosis and (2) a P2X $\mathrm{X}_{7} \mathrm{R}$ mediated form of necrosis (Fig. 9).

Exogenous ATP promotes the cellular depletion pathway. To further explore the role of ATP in LtxA mediated cell death, LtxA treatments were supplemented with exogenous ATP (bzATP) and apoptosis and cellular depletion were measured in both Jurkat wild-type and Panx1 K/O cells. Following LtxA stimulation of Jurkat wild-type cells, a clear distinction between the apoptotic and cellular depletion pathways is observed after $3 \mathrm{~h}$ (Fig. 10a). When LtxA was then supplemented with bzATP, the cellular depletion pathway was drastically increased (Fig. 10a). LtxA alone or in combination with bzATP did not promote apoptosis or cellular depletion in Panx $1 \mathrm{~K} / \mathrm{O}$ cells after $3 \mathrm{~h}$ of treatment (Fig. 10a). To determine if the resistance to cell death observed in the $\mathrm{K} / \mathrm{O}$ cells could be overcome, bzATP stimulation was increased from 3 to $18 \mathrm{~h}$. By increasing the bzATP treatment time and supplementing the treatment with LtxA, promotion of only the cellular depletion pathway in Panx1 K/O cells was observed (Fig. 10b).

Blockage of $\mathrm{P} 2 \mathrm{X}_{7} \mathrm{R}$ with oATP prevents intracellular $\mathrm{Ca}^{2+}$ mobilization in LtxA treated Jurkat cells. Mobilization of intracellular $\mathrm{Ca}^{2+}$ is one of the earliest and most important LtxA mediated events responsible for the cell death of Jurkat cells ${ }^{28,29}$. To determine if extracellular ATP plays a role in intracellular $\mathrm{Ca}^{2+}$ mobilization, the primary binding partner of ATP $\left(\mathrm{P} 2 \mathrm{X}_{7} \mathrm{R}\right)$ was blocked with oATP. We demonstrate that cytosolic $\mathrm{Ca}^{2+}$ mobilization was decreased to levels similar to that of untreated control cells when Jurkat cells antagonized with oATP were subsequently treated with LtxA (Fig. 11).

The role of ATP in LtxA mediated cell death. The proposed model describes the molecular sequence of events carried out during LtxA mediated cell death of Jurkat cells. LtxA first interacts with susceptible cells by binding to LFA-1 which is believed to be coupled to the Fas death receptor. This binding and interaction of LFA-1 to the membrane is then thought to initiate the controlled expulsion of ATP via Panx1 channels. The release of ATP then triggers intracellular $\mathrm{Ca}^{2+}$ mobilization, clustering of LFA-1 into lipid rafts, and subsequent cell death via apoptosis and necrosis. We additionally propose that the elevations in intracellular $\mathrm{Ca}^{2+}$ are dependent on the interaction between ATP and $\mathrm{P} 2 \mathrm{X}_{7} \mathrm{R}$. 


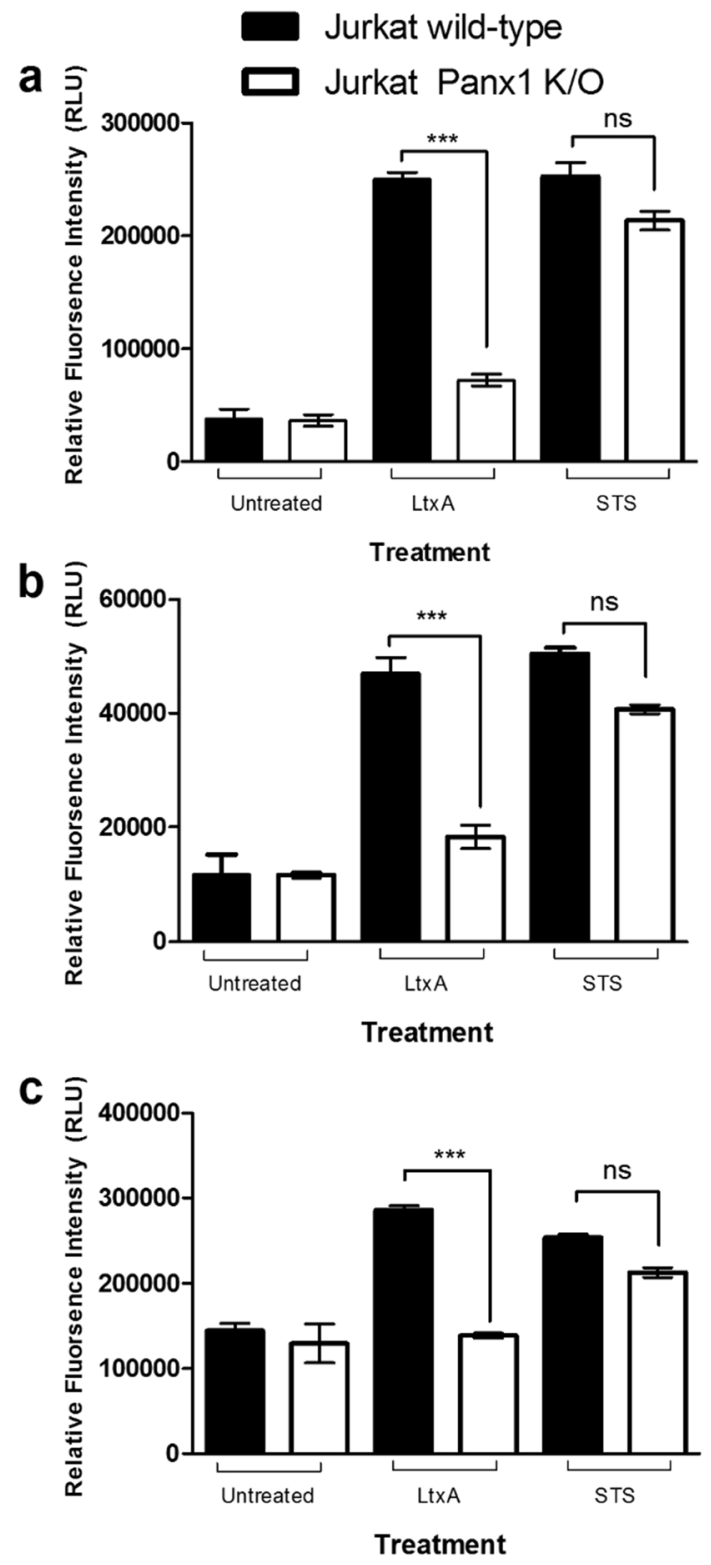

Figure 7. Caspase activation is inhibited in Panx1 K/O cells treated with LtxA. Jurkat wild-type and Panx1 K/O cells were treated with LtxA or STS for $3 \mathrm{~h}$. Cells were then measured for caspase cleavage for caspases 3/7 (a), 8 (b), and 9 (c) using the Caspase-Glo luminescent based microtiter assay from Promega. STS served as a positive control. ${ }^{* * *} \mathrm{p}<0.0001$.

\section{Discussion}

Extracellular ATP (eATP) has been shown to promote a variety of responses in T cells including CD27, CD23, and CD26L shedding, secretion of IL-2 and IFN- $\gamma$, cell proliferation, and antigen presentation ${ }^{30}$. Apoptotic cells have also been observed to release ATP and UTP (uridine-5'-triphosphate) at early stages of cell death via Panx 1 channels ${ }^{21}$. In this regard, the release of ATP from dying cells has been shown to promote the recruitment of leukocytes to the site of injury ${ }^{25}$. Studies with Jurkat lymphocytes and mouse thymocytes demonstrated caspase-3-dependent activation of Panx1 channels and consequent ATP release in response to the Fas-triggered induction of the extrinsic apoptotic cascade ${ }^{20}$. Knowing that LtxA triggers caspase activation and subsequent Fas mediated cell death in Jurkat cells, we investigated whether Panxl channels were responsible for the release of ATP and if this contributed to the cell death pathway(s) that we observed.

Following treatment with LtxA, we observed that Jurkat cell lymphocytes cleave caspases and PARP and stain positive for Annexin V (apoptotic marker) (Figs. 7, 8, 9). Despite being marked positive for apoptosis, we also observed that these LtxA treated cells also displayed relatively high levels of eATP compared to cells treated with staurosporin, an inducer of apoptosis (Fig. 1). We sought to better understand how this ATP was being utilized and its role in LtxA mediated cell death. 


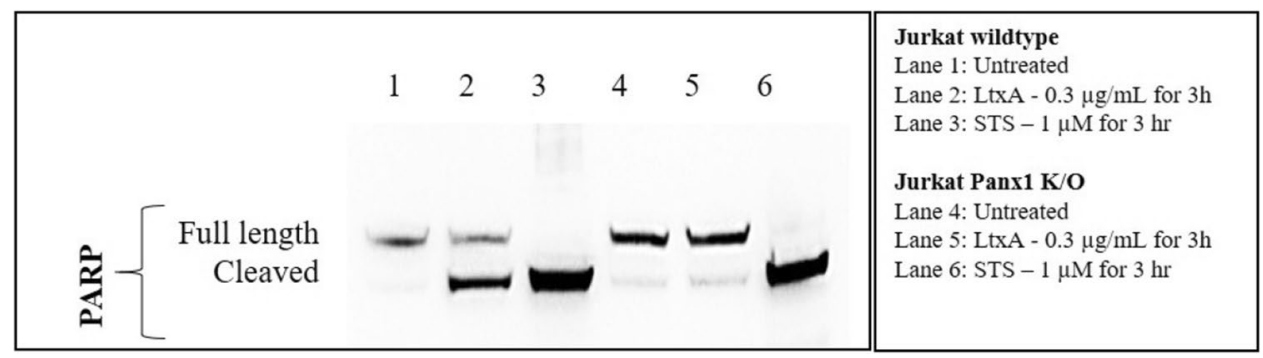

Figure 8. LtxA induced PARP cleavage in Jurkat Wildtype and Panx1 K/O cells. Wild-type and Panx1 K/O Jurkat cells were left untreated or treated with $0.3 \mu \mathrm{g} / \mathrm{mL}$ of LtxA or $1 \mu \mathrm{M}$ STS for $3 \mathrm{~h}$. Western blots were performed to determine the expression of PARP cleavage. While PARP cleavage was detected in LtxA and STS treated Jurkat wild-type cells and in STS treated Panx-1 K/O cells, no PARP cleavage was detected in LtxA treated Panx-1 K/O cells. $\beta$-Actin was used as the loading control (data not shown). The uncropped gel showing full-length and cleaved PARP is presented in Supplementary Figure S5.

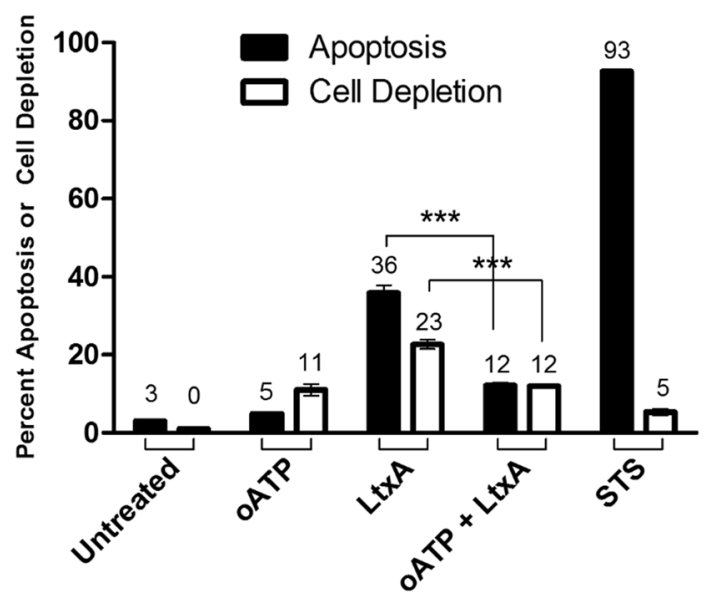

Figure 9. LtxA induces two distinct death pathways in Jurkat cells. Jurkat wild-type cells were treated with LtxA for $3 \mathrm{~h}$ with or without oATP. Without oATP, LtxA induces a distinct apoptotic population (Annexin V+) as well as a lytic population (cellular depletion). When Jurkat cells are pre-treated with oATP prior to LtxA treatment, the apoptotic population is decreased and the lytic population is inhibited.

We determined that ATP was being expelled from cells as a result of LtxA treatment and that the expulsion of ATP is an early event that is not a result of membrane disruption or lysis (Fig. 2). This is of interest because along with the over expression of LFA-1, leukemic leukocytes have been observed to overexpress Panx1 channels ${ }^{20-22,25,30}$. In fact, in response to certain cytotoxic agents, transformed lymphocytes have been observed to expel ATP in a controlled manner ${ }^{20-22}$.

As seen in Fig. 3, we were able to verify the presence of Panx1 in Jurkat cells via western blot analysis. Pretreating Jurkat cells with LtxA concentrations of $0.1 \mu \mathrm{g} / \mathrm{mL}$ for $1 \mathrm{~h}$ had no noticeable impact on the amount of protein observed, indicating that LtxA treatment does not appear to upregulate the production of Panxl protein. Since Panxl channels have been strongly associated with $\mathrm{P}_{2} \mathrm{X}_{7} \mathrm{Rs}$, we also assessed cell lysates for the presence of $\mathrm{P} 2 \mathrm{X}_{7} \mathrm{R}$ protein (Fig. 3). We observed that THP-1 cells displayed a Panx1 expression band of a much lower intensity when compared to the same population of Jurkat cells. This is important to note because while LtxA triggers ATP release and increased intracellular $\mathrm{Ca}^{2+}$ concentrations in THP-1 cells, the actual release of ATP from these cells appears to proceed with mechanisms independent of Panx 1 channels ${ }^{18}$. Taken together, we wished to know if the controlled expulsion of ATP was the result of Panx1 signaling and whether $\mathrm{P}_{2} \mathrm{X}_{7} \mathrm{R}$ expression also played a role in the LtxA mediated cell death of Jurkat cells.

To determine the potential role of Panx1 in the LtxA induced expulsion of ATP in Jurkat cells, CRISPR/Cas9 methodology was used to generate a Panx $1 \mathrm{~K} / \mathrm{O}$ cell line (Fig. 4). We determined that LtxA mediated expulsion of ATP was drastically reduced when Panx1 was knocked out (Fig. 5). While complete inhibition of eATP was not observed in Panx1 K/O cells, the released ATP is most likely the result of alternative release mechanisms engaging to compensate for the lack of Panx1.

In addition to the significant reduction of LtxA induced eATP, Panx1 K/O cells were also significantly more resistant to LtxA as cell death following LtxA treatments were similar to that of untreated control cells (Fig. 6). It is important to note that Panx1 K/O cells continued to be susceptible to cell death via staurosporin treatment, indicating that the molecular machinery responsible for initiating and carrying out the extrinsic apoptotic 
a

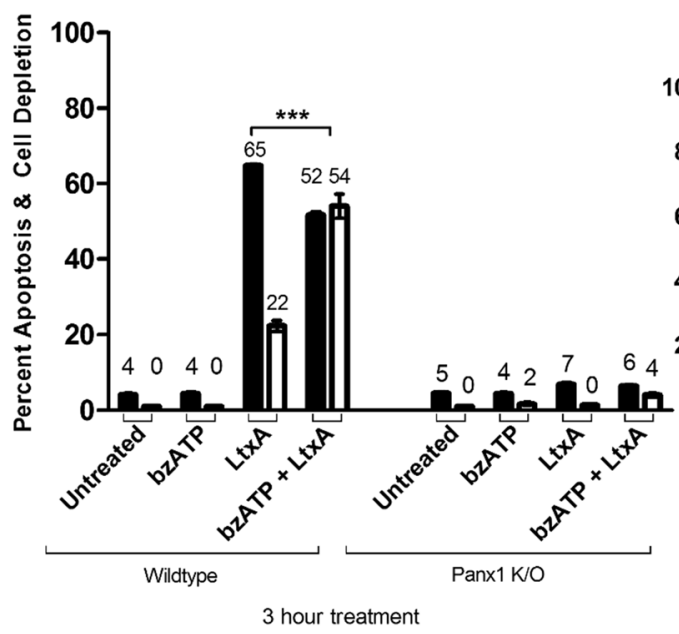

b

Figure 10. Addition of bzATP promotes LtxA mediated lysis in Jurkat wild-type and Panx1 K/O cells. Jurkat wild-type and Panx1 K/O cells were treated with LtxA with or without bzATP for 3 or $18 \mathrm{~h}$. In Jurkat wildtype cells, the addition of bzATP with LtxA promoted a cytolytic pathway independent of apoptosis in $3 \mathrm{~h}(\mathbf{a})$. Panx $1 \mathrm{~K} / \mathrm{O}$ cells remained resistant to LtxA and bzATP + LtxA induced apoptosis and lysis for $3 \mathrm{~h}$. When Panx1 K/O cells were stimulated with bzATP and LtxA overnight (b), a cytolytic pathway was observed but apoptosis remained deficient.

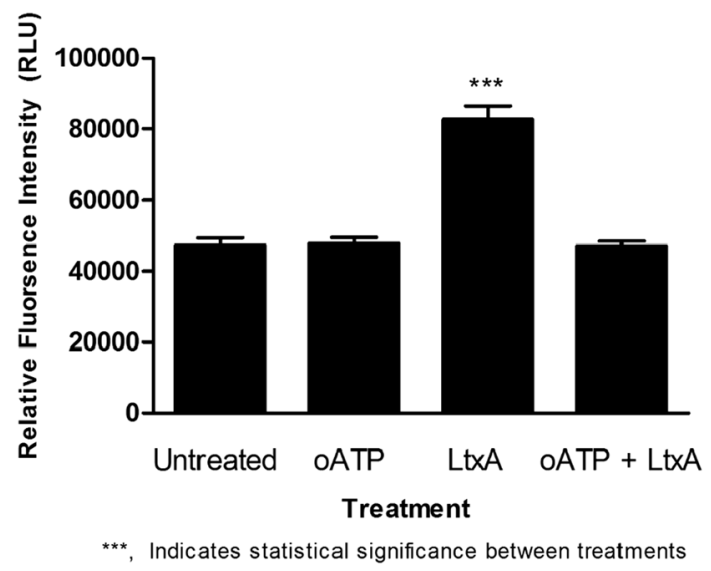

Figure 11. Intracellular $\mathrm{Ca}^{2+}$ mobilization of LtxA treated Jurkat cells. Jurkat cells were treated with LtxA alone or pre-treated with oATP following LtxA treatment and assessed for intracellular $\mathrm{Ca}^{2+}$ mobilization using a fluorescent based assay. Preventing the binding of ATP to $\mathrm{P} 2 \mathrm{X}_{7} \mathrm{R}$ using oATP reduced intracellular $\mathrm{Ca}^{2+}$ mobilization to that of untreated cell control levels. Where indicated, cells were pretreated with oATP at a concentration of $600 \mu \mathrm{M}$ for $1 \mathrm{~h}$ prior to LtxA treatment. LtxA was used at a concentration of $0.3 \mu \mathrm{g} / \mathrm{mL}$ for 30 min. ${ }^{* * *} \mathrm{p}<0.001$.

death pathway was not affected in Panx1 K/O cells (Fig. 6, STS control). To corroborate the LtxA resistance data generated through the Annexin $\mathrm{V}$ assay, caspase activation assays were also performed. As shown in Fig. 7, K/O of Panx1 reduced LtxA mediated caspase activation (-3/-7, -8, and -9) to control levels while having no effect on the activation of caspases via staurosporin. Further, the cleavage of PARP following treatment with LtxA was also reduced in Panx1 K/O cells (Fig. 8).

With the significant reductions in LtxA mediated cell death following Panx1 K/O, we examined whether Fas or LFA-1 surface expression was affected, as these two receptors are known to be critical for LtxA induced cell death of Jurkat cells ${ }^{19,31}$. Through flow cytometry, it was determined that there was no decrease in LFA-1 or Fas surface expression as the result of our CRISPR/Cas9 mediated K/O of Panx1 (data not shown). This indicates that there is a close connection between Panx1, ATP, PARP cleavage, and caspase activation in relation to LtxA induced cell death of Jurkat cells.

It is known that the activation of $\mathrm{P} 2 \mathrm{X}_{7} \mathrm{R}$ may lead to cytotoxicity and act in a way to upregulate cell death in response to pathological insults ${ }^{32}$. During pro-inflammatory responses and tissue injury, release of ATP into the extracellular environment has shown to activate $\mathrm{P}_{2} \mathrm{X}_{7} \mathrm{Rs}$, resulting in apoptotic and necrotic forms of cell 
death ${ }^{26,33}$. In murine thymocytes, ATP-mediated $\mathrm{P} 2 \mathrm{X}_{7} \mathrm{R}$ activation leads to death via both caspase-dependent apoptosis and necrosis/lysis, even though necrotic cell death is predominant ${ }^{26}$. Additionally, $\mathrm{P} 2 \mathrm{X}_{7} \mathrm{Rs}$ are involved in many types of leukemias, as ATP-induced activation of $\mathrm{P} 2 \mathrm{X}_{7} \mathrm{R}$ has been implicated to promote a diverse array of signaling events including apoptosis of certain types of leukemic B- and T-cells ${ }^{34-39}$. It has also been demonstrated that the Fas-L mediated death of Jurkat cells requires an ATP-dependent cross talk between Fas and $\mathrm{P} 2 \mathrm{X}_{7} \mathrm{R}^{35}$. The involvement of $\mathrm{P} 2 \mathrm{X}_{7} \mathrm{Rs}$ in LtxA treated macrophages has also been suggested, as macrophages and lymphocytes pre-treated with oATP, a $\mathrm{P} 2 \mathrm{X}_{7} \mathrm{R}$ antagonist, were less susceptible to cell death following certain treatments, such as Fas-L L $^{35,37,38,40}$. Since LtxA specifically binds to LFA-1, and LFA-1 appears to colocalize with Fas, it is possible that LtxA is initiating a similar $\mathrm{P}_{2} \mathrm{X}_{7} \mathrm{R}$-mediated response. For this reason, it was important to also investigate the potential involvement of this receptor.

To understand the involvement of $\mathrm{P}_{2} \mathrm{X}_{7} \mathrm{Rs}$, the receptor was physically blocked using oATP prior to LtxA treatment. OATP is an irreversible inhibitor of the macrophage purinergic receptor that works by covalently modifying the receptor's nucleotide binding proteins, preventing the binding of ATP/eATP ${ }^{27}$. Since previous studies indicated that stimulation of $\mathrm{P}_{2} \mathrm{X}_{7} \mathrm{R}$ via eATP could lead to both apoptotic and necrotic forms of cell death, we measured cellular depletion in addition to apoptosis. We determined that LtxA induces two distinct death pathways: (1) apoptosis and (2) a form of necrosis (Fig. 9). When P2X $\mathrm{X}_{7} \mathrm{R}$ was blocked with oATP, and the cells were subsequently treated with LtxA, the apoptotic pathway was decreased while cellular depletion was completely inhibited (Fig. 9). While we did not expect pretreatment with oATP to affect apoptosis as strongly as it did, we believe that the reason for the decrease in apoptosis following oATP treatment is due to a potential link between $\mathrm{P} 2 \mathrm{X}_{7} \mathrm{R}$ and $\mathrm{Panx} 1^{26}$. It is likely that the suppression of $\mathrm{P} 2 \mathrm{X}_{7} \mathrm{R}$ via oATP has a functional effect on Panx 1 thereby disrupting ATP release and suppressing or delaying the apoptotic pathway. This data supports the role of $\mathrm{P} 2 \mathrm{X}_{7} \mathrm{R}$ contributing to both the apoptotic and necrotic forms of LtxA induced cell death. Specifically, LtxA induced eATP and activation of $\mathrm{P}_{2} \mathrm{X}_{7} \mathrm{R}$ appears to be important with respect to the rate at which apoptosis can initiate and required for the necrotic cell death pathway.

To better understand the potential contribution of $\mathrm{P}_{2} \mathrm{X}_{7} \mathrm{R}$ as it relates to the two LtxA initiated death pathways, we investigated as to whether an environment high in eATP was contributing to either of the death pathways. To determine this, LtxA was supplemented with exogenous ATP (bzATP), and apoptosis and cellular depletion were measured in both Jurkat wild-type and Panx1 K/O cells. Based on other reports noting the involvement of exogenous ATP in cellular lysis ${ }^{41}$, and with the knowledge that LtxA initiates apoptotic and necrotic mediated death pathways, we expected that the addition of bzATP to both Jurkat wild-type and Panx1 K/O cells would result in activation of $\mathrm{P}_{2} \mathrm{X}_{7} \mathrm{Rs}$ and subsequent cytolysis (cell depletion). Following LtxA stimulation of Jurkat wild-type cells, a clear distinction between the apoptotic and cellular depletion pathways was observed (Figs. 9, 10). When LtxA was then supplemented with bzATP, the cellular depletion pathway was drastically increased (Fig. 10a). This increase in the cellular depletion pathway strongly hints at the combination of LtxA and bzATP promoting a necrotic mechanism of death. Interestingly, Panx1 K/O cells did not react to combinations of LtxA and bzATP as expected (Fig. 10a). We attribute this to the fact that Panx1 K/O cells do not expel ATP at the level of the wild-type cells, nor do they die via traditional caspase mediated death mechanisms following the LtxA concentrations and times studied here. Therefore, these cells are presumably less susceptible to LtxA and bzATP mediated death mechanisms. To determine if the defect could be overcome, bzATP stimulation was increased from 3 to $18 \mathrm{~h}$. By increasing the bzATP treatment time and supplementing the treatment with LtxA, we were able to promote the cellular depletion pathway in Panx1 K/O cells (Fig. 10b). We note that there was still little effect on apoptosis despite the increased exposure time of LtxA and bzATP. There are two possible explanations for this observation. The first is that Panxl functionality is required in promoting LtxA induced apoptosis and the second is that it is known that overtime LtxA can cause membrane damage. Together, this data further supports that LtxA works in combination with ATP to promote apoptotic and lytic modes of cell death in Jurkat cells. In addition to Panxl playing a role in the initiation of apoptosis, it also appears to be required for ATP expulsion, stimulation of $\mathrm{P} 2 \mathrm{X}_{7} \mathrm{Rs}$, and ultimately, cytolysis.

It is understood that the influx of intracellular $\mathrm{Ca}^{2+}$ is one of the earliest events known to be important for LtxA mediated cell death ${ }^{28,29}$. In fact, Fong et al. demonstrated that LtxA induces an LFA-1 independent elevation of cytosolic $\mathrm{Ca}^{2+}$ in Jurkat cells ${ }^{29}$. This early event leads to the subsequent activation of a cascade of events including calpain activation, talin cleavage, and mobilization and clustering of LFA- 1 within lipid rafts along the plasma membrane ${ }^{29}$. We report here that an additional early event is that of the expulsion of ATP, and when compromised, alters how the cell responds to LtxA and subsequent cell death. Shown in Figs. 1, 2, and 5, we demonstrate how LtxA expels ATP from susceptible Jurkat cells early and in a controlled manner. Given the early and important changes mediated by LtxA induced $\mathrm{Ca}^{2+}$ mobilization, we investigated whether expelled ATP played a role in the ability for cells to mobilize $\mathrm{Ca}^{2+}$.

We discovered that when blocking Jurkat $\mathrm{P}_{2} \mathrm{X}_{7}$ Rs with oATP and subsequently treating the cells with LtxA, cytosolic $\mathrm{Ca}^{2+}$ mobilization was decreased to levels of untreated control cells (Fig. 11). This data suggests that the early $\mathrm{Ca}^{2+}$ mobilization event induced by LtxA binding, which is responsible for initiating the downstream cascade of events leading to cell death, may rely on activation of $\mathrm{P}_{2} \mathrm{X}_{7} \mathrm{Rs}$. Understanding that ATP release from LtxA treated Jurkat cells occurs within seconds, it is possible that the release of ATP and its binding to P2X $\mathrm{X}_{7} \mathrm{R}$, and not intracellular $\mathrm{Ca}^{2+}$ mobilization, is the first event involved in the LtxA mediated cell death of Jurkat cells. If this is indeed the case, we would not be the first to demonstrate the ATP-induced propagation of calcium signals. Zumerle et al., for example, demonstrated in their work that triggered macrophages are able to release ATP and propagate calcium signals in untriggered bystander cells ${ }^{42}$. It has also been observed that binding of ATP to P2Y receptors increases inositol 1,4,5-triphosphate, releasing $\mathrm{Ca}^{2+}$ from the ER stores ${ }^{43}$. This released $\mathrm{Ca}^{2+}$ then goes on to activate single-membrane channels leading to further release of ATP and propagation of signals to neighboring cells ${ }^{43}$. 


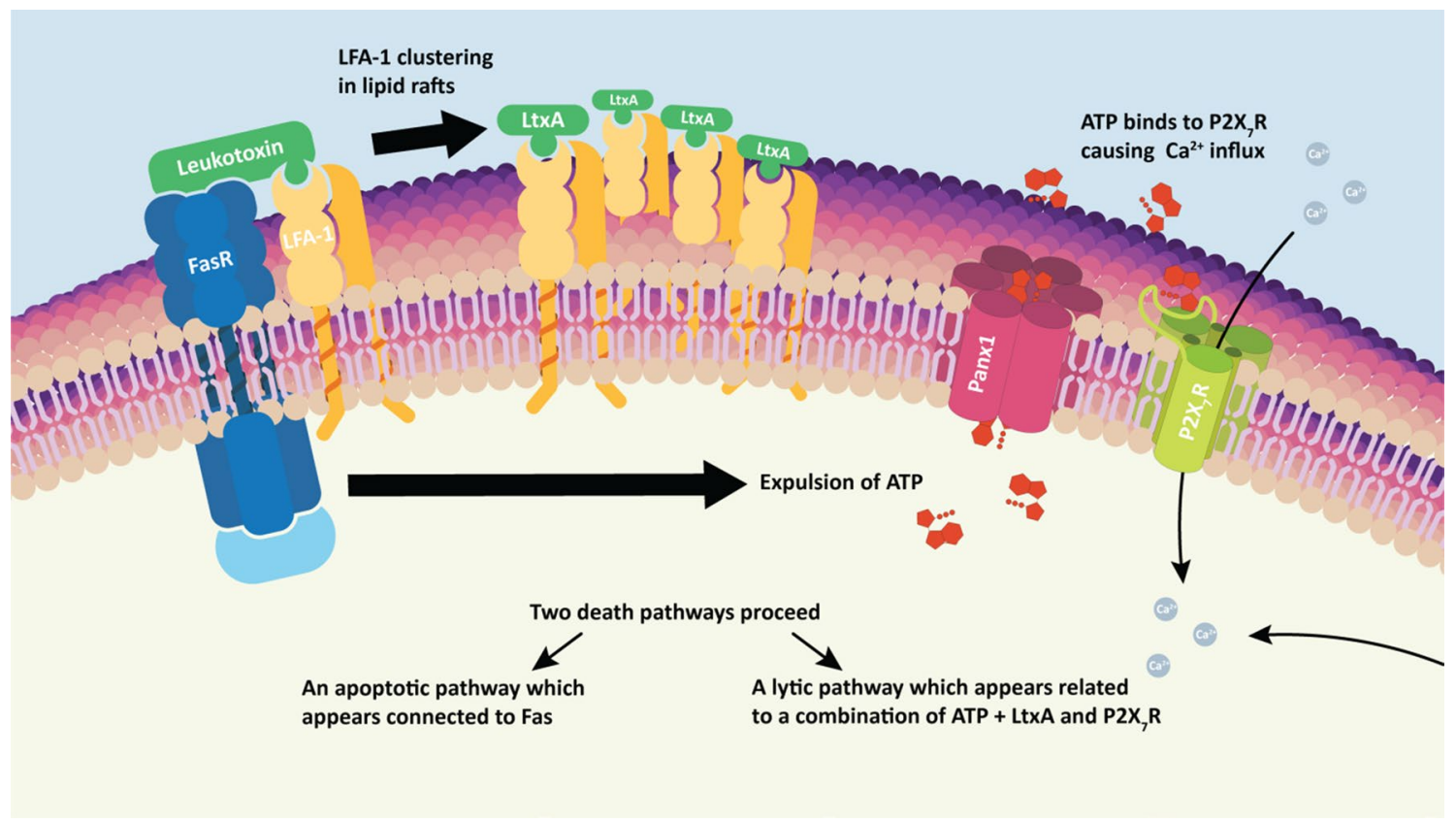

Figure 12. Proposed model. This model describes the proposed molecular sequence of events carried out during the LtxA mediated cell death of Jurkat cells. LtxA first interacts with susceptible cells by binding to LFA-1 which is believed to be coupled to the Fas death receptor. We show in this report that it appears that the next step following LtxA and membrane interaction is the controlled expulsion of ATP via Panx1 channels. The release of ATP then leads to intracellular $\mathrm{Ca}^{2+}$ mobilization, clustering of LFA-1 into lipid rafts, and subsequent cell death via apoptosis and necrosis. We additionally show that the elevations in intracellular $\mathrm{Ca}^{2+}$ appear to be dependent on ATPs interaction with the $\mathrm{P}_{2} \mathrm{X}_{7} \mathrm{R}$.

Here we report that the release of ATP is most likely the first step involved in LtxA mediated Jurkat cell death. eATP leads to the autocrine/paracrine activation of $\mathrm{P} 2 \mathrm{X}_{7}$ receptors which serves to propagate the mobilization of intracellular $\mathrm{Ca}^{2+}$, ultimately triggering the cascade of subsequent downstream events leading to cell death. For a summary of events, refer to the proposed model shown in Fig. 12.

\section{Materials and methods}

Cell lines and culture methods. Human white blood cell lines (Jurkat E6.1 and THP-1) were purchased from American Type Culture Collection [ATCC] (Manassas, VA). Knockout (K/O) cells deficient in Panx1 were generated using CRISPR/Cas9 gene editing methodology (necessary constructs and reagents were purchased from Invitrogen). All white blood cell lines were grown in Roswell Park Memorial Institute (RPMI) 1640 (Life Technologies) media supplemented with $10 \%$ heat inactivated (HI) fetal bovine serum (FBS; Life Technologies). In certain cases, $\mathrm{K} / \mathrm{O}$ cells were supplemented with blasticidin and/or puromycin to select for K/O only cells. All cells were maintained in a cell culture incubator set to $37^{\circ} \mathrm{C}$ and $5 \% \mathrm{CO}_{2}$.

Purification of LtxA. Leukotoxin was purified from cell culture supernatants of A. actinomycetemcomitans strain NJ4500. Additionally, an A. actinomycetemcomitans strain NJ4500 clone capable of growing in animal free media was isolated. LtxA purification procedures were developed and purified from culture supernatants at Paragon Biosciences (Baltimore, MD).

Flow cytometry. Apoptosis (Annexin). Cells $\left(1 \times 10^{6} / \mathrm{mL}\right)$ were treated with various concentrations of LtxA for indicated times. Following treatment, $100 \mu \mathrm{L}$ of treated cells were transferred to 96 -well black bottom plates. An aliquot of $100 \mu \mathrm{L}$ of Nexin reagent (Millipore) was then added to each well containing $100 \mu \mathrm{L}$ of cells. The plate was incubated in the dark and on a shaker for $10 \mathrm{~min}$. Following incubation, the luminescence was read using a microtiter plate reader (BioTek Synergy 2). Treatments were performed in triplicate and 5000-10,000 events were recorded. Apoptosis was determined as the percentage of Annexin $\mathrm{V}^{+}$cells relative to an untreated cell control.

Measurement of ATP and extracellular ATP. ATP and extracellular ATP was measured via CellTiterGlo, which catalyzes the oxidation of luciferin in the presence of ATP and produces luminescence. Cells $\left(1 \times 10^{6}\right)$ in media were left untreated or treated with concentrations of LtxA or STS in 24-well plates. Following treatment, $100 \mu \mathrm{L}$ of cells were transferred in triplicate into 96-well black wall and bottom plates and up to $100 \mu \mathrm{L}$ of CellTiter-Glo reagent was added to each well. For extracellular ATP analysis, the cells were centrifuged at $250 \mathrm{~g}$ for $5 \mathrm{~min}$ and $100 \mu \mathrm{L}$ of the supernatant was added prior to the addition of CellTiter-Glo. The plate was mixed 
on an orbital shaker for $2 \mathrm{~min}$. The plates were incubated at $10 \mathrm{~min}$ at room temperature. ATP (luminescence) was detected using a microtiter plate reader set to read the top of each well.

Measurement of caspase activity. Caspase activity was measured via Caspase-Glo, where caspase cleavage of the proluciferin DEVD substrate, a substrate for luciferase (aminoluciferin) is released, and in the presence of luciferase and ATP, results in the production of luminesce. Cells $\left(1 \times 10^{6}\right)$ in media were left untreated or treated with concentrations of LtxA or STS in 24-well plates. Following treatment, $100 \mu \mathrm{L}$ of cells were transferred in triplicate into 96-well black wall and bottom plates and $50 \mu \mathrm{L}$ of Caspase-Glo reagent was added to each well. Plates were incubated for $30 \mathrm{~min}$ at room temperature. Caspase activity (luminescence) was detected using a microtiter plate reader set to read the top of each well. The following Caspase-Glo assay systems were used for analysis: Caspase-Glo 3/7 assay (Cat. No. G8090). Caspase Glo 8 assay (Cat. No. G8200). Caspase Glo 9 assay (G8210).

CytoTox-ONE homogenous membrane integrity assay. Jurkat cells were collected at $1 \times 10^{6}$ cells/ $\mathrm{mL}$ and treated with concentrations of LtxA at various time points. At the end of the treatment, $100 \mu \mathrm{L}$ of each treatment sample was transferred to a 96-well plate in triplicate. For the positive control, $2 \mu \mathrm{L}$ of lysis reagent was then added to the appropriate wells in triplicate. Equal amounts of assay reagent were added to each well and the plate was incubated at room temperature for $10 \mathrm{~min}$. Stop solution $(50 \mu \mathrm{L})$ was then added to each well and the plate was transferred to a shaker for $10 \mathrm{~s}$. The plate was then read with an excitation wavelength of $560 \mathrm{~nm}$ and an emission wavelength of $590 \mathrm{~nm}$. Cytotoxicity was calculated using the following equation:

$$
\begin{aligned}
\text { Percent Cytotoxicity }= & 100 \times(\text { Experimental }- \text { Culture Medium Background }) / \\
& (\text { Maximum LDH Release }- \text { Culture Medium Background })
\end{aligned}
$$

Cell depletion assay. Cell depletion assays were performed by counting cells with an automated cell counter (BIO-RAD, TC-20). Following treatment, wells containing cells were mixed with a pipette and $10 \mu \mathrm{L}$ of cell suspension was transferred to an automated cell counting hemacytometer slide. The total cell count was recorded for three independent replicates and averaged. Percent depletion was calculated by dividing the treatment cells by the control cells and multiplying by 100 .

Western blot analysis. Cells $\left(1 \times 10^{6}\right)$ in media were left untreated or treated with various concentrations of LtxA. The cells were collected and centrifuged at $250 \mathrm{~g}$ for $5 \mathrm{~min}$. The pellet was washed two times with $1 \mathrm{~mL}$ of sterile DPBS (HyClone Cat\# SH30028.03). Following washing, pellets were resuspended with $100 \mu \mathrm{L}$ of $1 \times$ lysis buffer (Cell Signaling Cat\# 9803) diluted in sterile nuclease free water (Sigma Cat\# W4502) and supplemented with protease and phosphatase inhibitor cocktail (Sigma Cat\# PPC1010-1) at a ratio of $10 \mu \mathrm{L}$ per $1 \mathrm{~mL}$. The lysis buffer containing tubes were incubated at $4{ }^{\circ} \mathrm{C}$ for $30 \mathrm{~min}$. After $30 \mathrm{~min}, 25 \mu \mathrm{L}$ of NuPAGE LDS sample buffer ( $4 \times$ stock-Cat\# NP0008) was added to the tube and the tube was passed through QIAshredder columns (Qiagen Ref\# 79656) for $1 \mathrm{~min}$ at 20,000g. The flow through was collected and $5 \mu \mathrm{L}$ of 2-Mercaptoethanol (Sigma Cat\#M3148) was added. Each tube was then heated using a heat block set to $90{ }^{\circ} \mathrm{C}$ for $5 \mathrm{~min}$. The lysate tubes were transferred to an ice bucket and $10 \mu \mathrm{L}$ of lysate was loaded to each well of a precast NuPAGE Bis-4-12\% Tris Protein Gel (Invitrogen Cat\#NP0321) that was previously transferred to a X-Cell Surelock chamber containing $1 \mathrm{~L}$ of $1 \times$ NuPAGE MES SDS Running Buffer (Novex Ref\#NP0002). To at least one well, $5 \mu \mathrm{L}$ of Precision Plus Protein Dual Color Standards (BIORAD Cat\#161-0374) protein ladder was added and run at $200 \mathrm{~V}$ for 30-35 min. The protein bands were transferred to a nitrocellulose membrane using the iBlot 2 NC Mini Top and Bottom Stack System as per the manufacturer's instructions (Invitrogen Ref\# IB23002). The assembled stack was then transferred to the iBlot 2 Dry Blotting System (Invitrogen Cat\#IB21001) and the transfer was completed using the preprogrammed method recommended by the manufacturer: P0 ( $20 \mathrm{~V}$ for $1 \mathrm{~min}, 23 \mathrm{~V}$ for $4 \mathrm{~min}, 25 \mathrm{~V}$ for remainder-7-min run). The nitrocellulose membrane was removed from the assembly stack and kept wet with $1 \times$ wash buffer (PBS supplemented with $0.1 \%$ Tween 20 ) and then blocked with $5 \%$ nonfat dry milk prepared in $1 \times$ wash buffer for $1 \mathrm{~h}$ at room temperature on a shaker. The nitrocellulose membrane was then washed $3 \times$ for 5 min each with $1 \times$ wash buffer. The membrane was then probed with the appropriate antibody solution (1:1000) and left overnight on a shaker at $4{ }^{\circ} \mathrm{C}$. The membrane was then washed $3 \times$ for 5 min each with $1 \times$ wash buffer and probed with the secondary antibody conjugated with HRP (1:1000) for $1 \mathrm{~h}$ on a shaker at room temperature. The membrane was again washed $3 \times$ for 5 min each with $1 \times$ wash buffer. The membrane was then developed using a fresh solution of approximately $5-6 \mathrm{~mL}$ of chemiluminescence substrate Clarity Western ECL Substrate (BIO-RAD Cat\#170-5060). The protein bands were visualized using Molecular Imager ChemiDoc XRS+ Imaging System (BIO-RAD).

CRISPR/Cas9 knockout generation. Generation of Cas9 expressing Jurkat cell line. Jurkat cells at a volume of $20 \mathrm{~mL}$ and concentration of $1 \times 10^{5}$ cells/mL were prepared in RPMI supplemented with $10 \%$ HI FBS. Two sterile $15 \mathrm{~mL}$ conical tubes each containing $6 \mathrm{~mL}$ of the above cell suspension were supplemented with $8 \mu \mathrm{g} / \mathrm{mL}$ of polybrene (Santa Cruz Cat\#SC-134220). Ready to use Cas9 LentiArray Lentivirus (Invitrogen; Cat\# A32064) at a concentration of $>10^{7} \mathrm{TU} / \mathrm{mL}\left(10^{4} \mathrm{TU} / \mu \mathrm{L}\right)$ was removed from a $-80^{\circ} \mathrm{C}$ freezer and thawed until only small ice crystals remained. The lentiviral tube was then put on ice and $60 \mu \mathrm{L}$ was added to one of the conical tubes to achieve a multiplicity of infection (MOI) of $1\left(6 \times 10^{5}\right.$ lentiviral particles per $6 \times 10^{5}$ cells). The other conical tube did not receive lentiviral treatment and served as a negative control. Both conical tubes were centrifuged at $800 \mathrm{~g}$ at room temperature for $90 \mathrm{~min}$ to enhance surface binding and viral infectivity. Following 
centrifugation, the supernatant was carefully aspirated and the cells were resuspended with $6 \mathrm{~mL}$ of fresh medium and gently transferred to T- 25 cell culture flasks. The flasks were then incubated at $37^{\circ} \mathrm{C} / 5 \% \mathrm{CO}_{2}$ overnight $(\sim 18 \mathrm{~h})$ without any disruption. The following day, the cells were gently transferred from the T-25 flask to a new $15 \mathrm{~mL}$ conical tube. The tubes were spun down at $200 \mathrm{~g}$ for $5 \mathrm{~min}$. The supernatant was aspirated and the cells were resuspended with $6 \mathrm{~mL}$ of fresh RPMI and transferred to a new T-25 flask. At $72 \mathrm{~h}$ post transduction, $10 \mu \mathrm{g} /$ $\mathrm{mL}$ of blasticidin was added to the flasks and allowed to incubate with the cells for 7 days. Selection media was replaced every 3 days until the negative control cells were dead.

Single cell clone isolation. The Cas9 expressing Jurkat cells were kept incubating and allowed to further expand. Isolation of a single clone was achieved by performing the limiting dilution cloning (LDC) assay directly from the pool of stable transductants (i.e., Blasticidin-resistant cells). Blasticidin resistant cells were serially diluted to a final concentration of 5 cells $/ \mathrm{mL}(0.5$ cells $/ 100 \mu \mathrm{L})$ using RPMI supplemented with $10 \mu \mathrm{g} / \mathrm{mL}$ of blasticidin. Using a multi-channel pipette, $100 \mu \mathrm{L}$ of the cells were transferred into individual wells of a 96 -well plate. The plates were incubated at $37^{\circ} \mathrm{C}$ in a humidified $5 \% \mathrm{CO}_{2}$ incubator and replaced with fresh blasticidin containing medium every 3-4 days. After 10-12 days of incubation, the wells were visually inspected under a microscope to identify which wells displayed evidence of colonies that derived from a single cell (monoclonal cells). Once identified, the monoclonal cells were transferred to a 24-well plate containing RPMI with blasticidin. The cells were incubated at $37^{\circ} \mathrm{C}$ and scaled up every 2-5 days by transferring each clonal population into a larger plate or vessel (i.e., from 24 -well plates to 6-well plates or T-25 flasks, and then to T-75 flasks). Once healthy and expanded clonal populations had been achieved, five vials from each clone were cryopreserved and assessed for cell morphology, growth kinetics, and Cas9 protein expression.

Generation of Pannexin-1 CRISPR/Cas9 knockout. A 24 -well plate containing $5 \times 10^{4}$ of Jurkat cells stably expressing Cas 9 nuclease were expanded by incubating the cells at $37{ }^{\circ} \mathrm{C} / 5 \% \mathrm{CO}_{2}$. Transduction medium was prepared by adding sgRNA lentiviral particles (Dharmacon, Cat\# VSGH10148-EG24145) to prewarmed RPMI at an MOI of 0.3 . The cells were then further incubated at $37^{\circ} \mathrm{C} / 5 \% \mathrm{CO}_{2}$ for $4-6 \mathrm{~h}$. At $24-48 \mathrm{~h}$ post-transduction, the medium was replaced with selection medium (RPMI w/10\% HI-FBS supplemented with $0.6 \mu \mathrm{g} / \mathrm{mL}$ of puromycin and $10 \mu \mathrm{g} / \mathrm{mL}$ of blasticidin). The selection medium was replaced every 2-3 days and the presence of dead cells was assessed daily. Once the cells were determined to be growing normally in selection medium, they were expanded, and aliquots were prepared for cryopreservation. Single cell clonal expansion was again performed. Western blots were performed to determine which knockout resulted in the highest knock down efficiency.

Calcium $\left(\mathrm{Ca}^{2+}\right)$ mobilization. Cells were treated in a 24 -well plate and then centrifuged at $430 \mathrm{~g}$ for $5 \mathrm{~min}$. The cells were then suspended in $100 \mu \mathrm{L}$ of fluo-8 dye loading solution and transferred to a 96-well poly-D-lysin plate (Abcam ab112129). The plate was immediately centrifuged at $120 \mathrm{~g}$ for $2 \mathrm{~min}$ and incubated at $37^{\circ} \mathrm{C} / 5 \%$ $\mathrm{CO}_{2}$ for $30 \mathrm{~min}$ and then incubated at room temperature for an additional $30 \mathrm{~min}$. The calcium flux assay was performed by monitoring the fluorescence intensity at $\mathrm{Ex} / \mathrm{Em}=490 / 525 \mathrm{~nm}$.

Statistical analysis. Bars on graphs represent the means from at least three independent experiments and error bars represent the standard error of the mean (SEM). Standard error was calculated as standard deviation/sq rt (sample size). For statistical analyses, data were subjected to an unpaired 2-tailed Student's $t$ test, with $\mathrm{p} \leq 0.05$ considered to be statistically significant. All calculations were performed using GraphPad Prism Software. ${ }^{*} \mathrm{p} \leq 0.05,{ }^{* *} \mathrm{p} \leq 0.01,{ }^{* * *} \mathrm{p} \leq 0.001$.

\section{Data availability}

The datasets generated during and/or analyzed during the current study are available from the corresponding author on reasonable request.

Received: 12 April 2021; Accepted: 26 August 2021

Published online: 10 September 2021

\section{References}

1. Scuron, M. D., Boesze-Battaglia, K., Dlakic, M. \& Shenker, B. J. The cytolethal distending toxin contributes to microbial virulence and disease pathogenesis by acting as a tri-perditious toxin. Front. Cell Infect. Microbiol. 6, 168. https://doi.org/10.3389/fcimb. 2016.00168 (2016).

2. Haubek, D. \& Johansson, A. Pathogenicity of the highly leukotoxic JP2 clone of Aggregatibacter actinomycetemcomitans and its geographic dissemination and role in aggressive periodontitis. J. Oral Microbiol. https://doi.org/10.3402/jom.v6.23980 (2014).

3. Kachlany, S. C. Aggregatibacter actinomycetemcomitans leukotoxin: From threat to therapy. J. Dent. Res. 89, 561-570. https://doi. org/10.1177/0022034510363682 (2010).

4. DiFranco, K. M. et al. LFA-1-targeting Leukotoxin (LtxA; Leukothera(R)) causes lymphoma tumor regression in a humanized mouse model and requires caspase- 8 and Fas to kill malignant lymphocytes. Leuk. Res. 39, 649-656. https://doi.org/10.1016/j. leukres.2015.03.010(2015).

5. Kaur, M. \& Kachlany, S. C. Aggregatibacter actinomycetemcomitans leukotoxin (LtxA; Leukothera) induces cofilin dephosphorylation and actin depolymerization during killing of malignant monocytes. Microbiology 160, 2443-2452. https://doi.org/10.1099/ mic.0.082347-0 (2014).

6. Wang, Y. et al. LFA-1 affinity regulation is necessary for the activation and proliferation of naive T cells. J. Biol. Chem. 284, 12645-12653. https://doi.org/10.1074/jbc.M807207200 (2009).

7. Evans, R. et al. Integrins in immunity. J. Cell Sci. 122, 215-225. https://doi.org/10.1242/jcs.019117 (2009).

8. Gupta, A. et al. Expression and targeting of lymphocyte function-associated antigen 1 (LFA-1) on white blood cells for treatment of allergic asthma. J. Leukoc. Biol. 97, 439-446. https://doi.org/10.1189/jlb.5HI0414-196R (2015). 
9. Kachlany, S. C. Mechanisms of LtxA (leukotoxin), a potent new anti-inflammatory agent for the treatment of alopecia areata. J. Investig. Dermatol. Symp. Proc. 17, 19-22. https://doi.org/10.1038/jidsymp.2015.34 (2015).

10. Stenderup, K. et al. Resolution of psoriasis by a leukocyte-targeting bacterial protein in a humanized mouse model. J. Investig. Dermatol. 131, 2033-2039. https://doi.org/10.1038/jid.2011.161 (2011).

11. Bechter, O. E. et al. Expression of LFA-1 identifies different prognostic subgroups in patients with advanced follicle center lymphoma (FCL). Leuk. Res. 23, 483-488 (1999).

12. Horst, E. et al. Expression of the leucocyte integrin LFA-1 (CD11a/CD18) and its ligand ICAM-1 (CD54) in lymphoid malignancies is related to lineage derivation and stage of differentiation but not to tumor grade. Leukemia 5, 848-853 (1991).

13. Inghirami, G. et al. Differential expression of LFA-1 molecules in non-Hodgkin's lymphoma and lymphoid leukemia. Blood 72, 1431-1434 (1988).

14. Simpson, D. L., Berthold, P. \& Taichman, N. S. Killing of human myelomonocytic leukemia and lymphocytic cell lines by Actinobacillus actinomycetemcomitans leukotoxin. Infect. Immun. 56, 1162-1166 (1988).

15. Skals, M. et al. Bacterial RTX toxins allow acute ATP release from human erythrocytes directly through the toxin pore. J. Biol. Chem. 289, 19098-19109. https://doi.org/10.1074/jbc.M114.571414 (2014).

16. Kachlany, S. C. et al. Anti-leukemia activity of a bacterial toxin with natural specificity for LFA-1 on white blood cells. Leuk. Res. 34, 777-785. https://doi.org/10.1016/j.leukres.2009.08.022 (2010).

17. DiFranco, K. M. et al. Leukotoxin (Leukothera(R)) targets active leukocyte function antigen-1 (LFA-1) protein and triggers a lysosomal mediated cell death pathway. J. Biol. Chem. 287, 17618-17627. https://doi.org/10.1074/jbc.M111.314674 (2012).

18. Fagerberg, S. K., Jakobsen, M. R., Skals, M. \& Praetorius, H. A. Inhibition of P2X receptors protects human monocytes against damage by leukotoxin from Aggregatibacter actinomycetemcomitans and $\alpha$-hemolysin from Escherichia coli. Infect. Immun. 84, 3114-3130. https://doi.org/10.1128/IAI.00674-16 (2016).

19. Vega, B. A., Schober, L. T., Kim, T., Belinka, B. A. Jr. \& Kachlany, S. C. Aggregatibacter actinomycetemcomitans leukotoxin (LtxA) requires death receptor fas, in addition to LFA-1, to trigger cell death in T lymphocytes. Infect. Immun. https://doi.org/10.1128/ IAI.00309-19 (2019).

20. Boyd-Tressler, A., Penuela, S., Laird, D. W. \& Dubyak, G. R. Chemotherapeutic drugs induce ATP release via caspase-gated pannexin-1 channels and a caspase/pannexin-1-independent mechanism. J. Biol. Chem. 289, 27246-27263. https://doi.org/10.1074/ jbc.M114.590240 (2014).

21. Martins, I. et al. Chemotherapy induces ATP release from tumor cells. Cell Cycle 8, 3723-3728. https://doi.org/10.4161/cc.8.22. 10026 (2009).

22. Martins, I. et al. Molecular mechanisms of ATP secretion during immunogenic cell death. Cell Death Differ. 21, 79-91. https:// doi.org/10.1038/cdd.2013.75 (2014).

23. Yip, L. et al. Autocrine regulation of T-cell activation by ATP release and P2X7 receptors. FASEB J. 23, 1685-1693. https://doi.org/ 10.1096/f.08-126458 (2009).

24. Lohman, A. W. \& Isakson, B. E. Differentiating connexin hemichannels and pannexin channels in cellular ATP release. FEBS Lett. 588, 1379-1388. https://doi.org/10.1016/j.febslet.2014.02.004 (2014).

25. Crespo Yanguas, S. et al. Pannexin1 as mediator of inflammation and cell death. Biochim. Biophys. Acta Mol. Cell Res. 1864, 51-61. https://doi.org/10.1016/j.bbamcr.2016.10.006 (2017).

26. Jun, D. J. et al. Extracellular ATP mediates necrotic cell swelling in SN4741 dopaminergic neurons through P2X7 receptors. J. Biol. Chem. 282, 37350-37358. https://doi.org/10.1074/jbc.M707915200 (2007).

27. Beigi, R. D., Kertesy, S. B., Aquilina, G. \& Dubyak, G. R. Oxidized ATP (oATP) attenuates proinflammatory signaling via P2 receptor-independent mechanisms. Br. J. Pharmacol. 140, 507-519. https://doi.org/10.1038/sj.bjp.0705470 (2003).

28. Fong, K. P. et al. Actinobacillus actinomycetemcomitans leukotoxin requires lipid microdomains for target cell cytotoxicity. Cell Microbiol. 8, 1753-1767. https://doi.org/10.1111/j.1462-5822.2006.00746.x (2006).

29. Fong, K. P. et al. Aggregatibacter actinomycetemcomitans leukotoxin is post-translationally modified by addition of either saturated or hydroxylated fatty acyl chains. Mol. Oral Microbiol. 26, 262-276. https://doi.org/10.1111/j.2041-1014.2011.00617.x (2011).

30. Shoji, K. F., Saez, P. J., Harcha, P. A., Aguila, H. L. \& Saez, J. C. Pannexin1 channels act downstream of P2X 7 receptors in ATPinduced murine T-cell death. Channels (Austin) 8, 142-156. https://doi.org/10.4161/chan.28122 (2014).

31. Vega, B. A., Belinka, B. A. Jr. \& Kachlany, S. C. Aggregatibacter actinomycetemcomitans Leukotoxin (LtxA; Leukothera((R))): Mechanisms of action and therapeutic applications. Toxins (Basel) https://doi.org/10.3390/toxins11090489 (2019).

32. Inoue, K. Microglial activation by purines and pyrimidines. Glia 40, 156-163. https://doi.org/10.1002/glia.10150 (2002).

33. Adinolfi, E. et al. Basal activation of the P2X7 ATP receptor elevates mitochondrial calcium and potential, increases cellular ATP levels, and promotes serum-independent growth. Mol. Biol. Cell 16, 3260-3272. https://doi.org/10.1091/mbc.e04-11-1025 (2005).

34. Adinolfi, E. et al. P2X7 receptor expression in evolutive and indolent forms of chronic B lymphocytic leukemia. Blood 99, 706-708. https://doi.org/10.1182/blood.v99.2.706 (2002).

35. Aguirre, A., Shoji, K. F., Saez, J. C., Henriquez, M. \& Quest, A. F. FasL-triggered death of Jurkat cells requires caspase 8-induced, ATP-dependent cross-talk between Fas and the purinergic receptor P2X(7). J. Cell Physiol. 228, 485-493. https://doi.org/10.1002/ jcp.24159 (2013).

36. Budagian, V. et al. Signaling through P2X7 receptor in human T cells involves p561ck, MAP kinases, and transcription factors AP-1 and NF-kappa B. J. Biol. Chem. 278, 1549-1560. https://doi.org/10.1074/jbc.M206383200 (2003).

37. Costa-Junior, H. M., Marques-da-Silva, C., Vieira, F. S., Moncao-Ribeiro, L. C. \& Coutinho-Silva, R. Lipid metabolism modulation by the P2X7 receptor in the immune system and during the course of infection: New insights into the old view. Purinergic Signal 7, 381-392. https://doi.org/10.1007/s11302-011-9255-6 (2011).

38. Kelk, P. et al. Cellular and molecular response of human macrophages exposed to Aggregatibacter actinomycetemcomitans leukotoxin. Cell Death Dis. 2, e126. https://doi.org/10.1038/cddis.2011.6 (2011).

39. Wiley, J. S. et al. A loss-of-function polymorphic mutation in the cytolytic P2X7 receptor gene and chronic lymphocytic leukaemia: A molecular study. Lancet 359, 1114-1119. https://doi.org/10.1016/S0140-6736(02)08156-4 (2002).

40. Bao, L., Locovei, S. \& Dahl, G. Pannexin membrane channels are mechanosensitive conduits for ATP. FEBS Lett. 572, 65-68. https://doi.org/10.1016/j.febslet.2004.07.009 (2004).

41. Blanchard, D. K. et al. Role of extracellular adenosine triphosphate in the cytotoxic T-lymphocyte-mediated lysis of antigen presenting cells. Blood 85, 3173-3182 (1995).

42. Zumerle, S. et al. Intercellular calcium signaling induced by ATP potentiates macrophage phagocytosis. Cell Rep. 27, 1-10 e14. https://doi.org/10.1016/i.celrep.2019.03.011 (2019).

43. Penuela, S., Gehi, R. \& Laird, D. W. The biochemistry and function of pannexin channels. Biochim. Biophys. Acta 1828, 15-22. https://doi.org/10.1016/j.bbamem.2012.01.017 (1828).

\section{Acknowledgements}

This work was supported by a small business grant from the National Cancer Institute (R41CA173900). We thank Brian Vega for helpful discussions throughout the study. All figures were created by the authors. The proposed model design was prepared by a third-party designer. The authors maintain all ownership and publishing rights of the model. 


\section{Author contributions}

D.J.P., D.P., and S.C.K. designed the experiments and analyzed data. D.J.P. and D.P. performed the experiments. D.J.P. and S.C.K. wrote the manuscript.

\section{Competing interests}

S.C.K. declares competing interests in the form of stock ownership in the company (Actinobac Biomed, Inc.) that has licensed the use of leukotoxin. In addition, S.C.K. has received consulting fees from this company. There are no other conflicts of interest to declare.

\section{Additional information}

Supplementary Information The online version contains supplementary material available at https://doi.org/ 10.1038/s41598-021-97545-4.

Correspondence and requests for materials should be addressed to S.C.K.

Reprints and permissions information is available at www.nature.com/reprints.

Publisher's note Springer Nature remains neutral with regard to jurisdictional claims in published maps and institutional affiliations.

(c) (i) Open Access This article is licensed under a Creative Commons Attribution 4.0 International License, which permits use, sharing, adaptation, distribution and reproduction in any medium or format, as long as you give appropriate credit to the original author(s) and the source, provide a link to the Creative Commons licence, and indicate if changes were made. The images or other third party material in this article are included in the article's Creative Commons licence, unless indicated otherwise in a credit line to the material. If material is not included in the article's Creative Commons licence and your intended use is not permitted by statutory regulation or exceeds the permitted use, you will need to obtain permission directly from the copyright holder. To view a copy of this licence, visit http://creativecommons.org/licenses/by/4.0/.

(C) The Author(s) 2021 